\title{
Hepatocyte growth factor enhances the barrier function in primary cultures of rat brain microvascular endothelial cells
}

\author{
Narumi Yamada a, b, Shinsuke Nakagawa c, d, *, Shoji Horai c, Kunihiko Tanaka c, \\ Maria A. Deli e , Hiroshi Yatsuhashi ${ }^{\text {a, b}}$, Masami Niwa ${ }^{\text {c, d, } 1}$
}

${ }^{a}$ Clinical Research Center, National Hospital Organization Nagasaki Medical Center, 2-1001-1 Kubara, Omura 856-8562, Japan

${ }^{b}$ Department of Hepatology, Nagasaki University Graduate School of Biomedical Sciences, 2-1001-1 Kubara, Omura 856-8562, Japan

${ }^{c}$ Department of Pharmacology, Nagasaki University Graduate School of Biomedical Sciences, 1-12-4 Sakamoto, Nagasaki 852-8523, Japan

d BBB Laboratory, PharmaCo-Cell Company, Ltd., 1-43 Dejima, Nagasaki 850-0862, Japan

${ }^{e}$ Laboratory of Molecular Neurobiology, Institute of Biophysics, Biological Research Center, Hungarian Academy of Sciences, Szeged, Hungary

${ }^{1}$ Professor emeritus at Nagasaki University

* Corresponding author. Department of Pharmacology, Nagasaki University Graduate School of Biomedical Sciences, 1-12-4 Sakamoto, Nagasaki 852-8523, Japan

E-mail address: shin3@nagasaki-u.ac.jp (S. Nakagawa)

Tel: +81-95-819-7043

Fax: +91-95-819-7044 


\begin{abstract}
The effects of hepatocyte growth factor (HGF) on barrier functions were investigated by a blood-brain barrier (BBB) in vitro model comprising a primary culture of rat brain capillary endothelial cells (RBEC). In order to examine the response of the peripheral endothelial cells to HGF, human umbilical vascular endothelial cells (HUVEC) and human dermal microvascular endothelial cells (HMVEC) were also treated with HGF. HGF decreased the permeability of RBEC to sodium fluorescein and Evans blue albumin, and dose-dependently increased transendothelial electrical resistance (TEER) in RBEC. HGF altered the immunochemical staining pattern of F-actin bands and made ZO-1 staining more distinct on the linear cell borders in RBEC. In contrast, HGF increased sodium fluorescein and Evans blue albumin permeability in HMVEC and HUVEC, and decreased TEER in HMVEC. In HMVEC, HGF reduced cortical actin bands and increased stress fiber density, and increased the zipper-like appearance of ZO-1 staining. Western blot analysis showed that HGF significantly increased the amount of ZO-1 and VE-cadherin. HGF seems to act on the BBB to strengthen BBB integrity. These finding indicated that cytoskeletal rearrangement and cell-cell adhesion, such as through VE-cadherin and ZO-1, are candidate mechanisms for the influence of HGF on the BBB. The possibility that HGF has therapeutic significance in protecting the BBB from damage needs to be considered.
\end{abstract}

Keywords: Hepatocyte growth factor, Blood-brain barrier, Tight junctions, Adherens junction, F-actin, ZO-1, VE-cadherin, Peripheral endothelial cells, TEER, permeability 


\section{Introduction}

Endothelial cells in the blood vessels of different organs possess different characteristics, and are regulated by specific local signals (Aird, 2007; Regan and Aird, 2012). Brain capillary endothelial cells forming the anatomical basis of the blood-brain barrier (BBB) have a highly specialized system for regulating the passage of substances from the blood into the brain parenchyma. The specialized BBB function is regulated by cross-talk with its neighboring cells, such as astrocytes, pericytes, perivascular microglia, and neurons (Abbott et al., 2010; Cecchelli et al., 2007). These cell-cell interactions within neurovascular units also contribute to the induction of the highly organized cell-cell adhesion system comprising tight junctions (TJs) and adherens junctions (AJs), which are associated with cytoskeletal actin in brain capillary endothelial cells (Giepmans and Ijzendoorn, 2009; Abbott et al., 2010). The TJs act as key players in brain homeostasis by controlling paracellular permeability between brain endothelial cells. Transmembrane TJ proteins, such as occludin and claudins, are linked to the actin cytoskeleton by $\mathrm{TJ}$ accessory proteins such as zonula occludens (ZO)-1, ZO-2, and ZO-3. AJs consist of transmembrane cadherins and cytoplasmic attached catenins, and act as molecules for cell-cell adhesion. Evidence suggests that disruptions of adhesion between brain capillary endothelial cells play a role in the onset and progression of central nervous system (CNS) disorders (Zlokovic, 2008; Quaegebeur et al., 2011; Hermann and Elali, 2012). Therefore, protection of the barrier function of the BBB may be important in preventing the development of CNS disease.

The multifunctional protein HGF, also known as scatter factor, is closely related to the induction of cell proliferation, motility, morphogenesis, and survival, as well as 
angiogenesis, in various cell types (Matsumoto and Nakamura, 1996; Trusolino et al., 2010). HGF receptor, a product of the proto-oncogene c-Met, is a heterodimeric transmembrane glycoprotein that has tyrosine-kinase activity and is expressed in various types of cells (Maulik et al., 2002; Trusolino et al., 2010). Binding of HGF to c-Met induces autophosphorylation of a single multifunctional site, and triggers a pleiotropic response involving multiple signal transducers, such as small GTPase Rac, mitogen-activated protein (MAP), protein kinase C (PKC), phosphatidylinositol-3-kinase (PI3-kinase), and its downstream effector glycogen

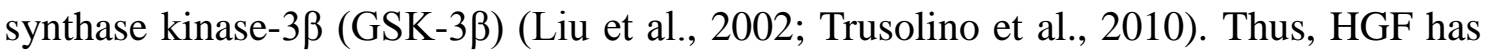
various effects that evoke diverse responses in different cells and tissues. These signals also affect TJ function and cytoskeleton remodeling in endothelial/epithelial cells. In fact, several reports indicate that HGF alters the permeability or electrical resistance in these cells. However, it seems that treatment of endothelial/epithelial cells with HGF has variable effects on barrier function depending on the report (Nusrat et al., 1994; Jiang et al., 1999; Martin et al., 2002, 2004; Pollack et al., 2004; Singleton et al., 2007). One aim of this study was to examine the effect of HGF on endothelial cells derived from different tissues, peripheral and brain.

Evidence for the presence of HGF and c-Met in both developing and adult mammalian brains (Honda et al., 1995; Achim et al., 1997) implies that HGF has an important role as a neurotrophic factor. In fact, recent studies indicate that HGF prevents neuronal cell death and attenuates learning dysfunction in a rat ischemia model in vivo (Miyazawa et al., 1998; Date et al., 2004). Additionally, HGF improves the hyperpermeability of the BBB induced by cerebral ischemia in vivo (Shimamura et al., 2004; Date et al., 2006). These findings indicate that HGF has potential as a BBB 
protective drug to strengthen the barrier function in brain endothelial cells. However, the effects of HGF on TJ function of the BBB are not well understood. Here, we studied the in vitro effect of HGF on cultured rat brain microvessel endothelial cells and peripheral vascular endothelial cells to elucidate the physiological significance of HGF on the BBB.

\section{Materials and Methods}

All reagents were purchased from Sigma (St. Louis, MO, USA) unless otherwise indicated. Wistar rats were obtained from Japan SLC, Inc. (Hamamatsu, Japan). All animals were treated in strict accordance with National Institutes of Health Guidelines for the Care and Use of Laboratory Animals (NIH Publications No. 80-23) and approved by the Nagasaki University Animal Care Committee.

Rat brain microvascular endothelial cells (RBEC)

Primary cultures of RBEC were prepared from 3-week-old rats as described previously (Nakagawa et al., 2007, 2009). Meninges were carefully removed from the forebrains and gray matter was minced into small pieces of approximately $1 \mathrm{~mm}^{3}$ in ice-cold Dulbecco's modified Eagle’s medium (DMEM), followed by dissociation with 25 up-and-down strokes using a 5-ml pipette in DMEM containing collagenase type 2 (1 mg/ml, Worthington Biochemical Corp., Lakewood, NJ, USA), DNase (15 $\mu \mathrm{g} / \mathrm{ml})$, and gentamycin $(50 \mu \mathrm{g} / \mathrm{ml})$, then followed by digestion in a shaker for $1.5 \mathrm{~h}$ at $37^{\circ} \mathrm{C}$. The cell pellet was separated by centrifugation in $20 \%$ bovine serum albumin (BSA)-DMEM $(1,000 \times g, 20 \mathrm{~min})$. The microvessels obtained in the pellet were further digested with collagenase-dispase (1 mg/ml; Roche Applied Sciences, Switzerland) and DNase $(6.7 \mu \mathrm{g} / \mathrm{ml})$ in DMEM for $1 \mathrm{~h}$ at $37^{\circ} \mathrm{C}$. Microvessel endothelial cell clusters were separated on a 33\% continuous Percoll (Pharmacia, Sweden) gradient, and were then 
collected and washed twice in DMEM before plating on 35-mm plastic dishes coated with collagen type IV and fibronectin (both $0.1 \mathrm{mg} / \mathrm{ml}$ ) (Day 0, Fig. 1).

RBEC cultures were maintained for 2 days in DMEM/F12 supplemented with 10\% plasma derived serum (PDS, Animal Technologies, Inc., Tyler, TX USA), basic fibroblast growth factor (bFGF, $1.5 \mathrm{ng} / \mathrm{mL}$; Roche Applied Sciences), heparin (100 $\mu \mathrm{g} / \mathrm{ml}$ ), insulin $(5 \mu \mathrm{g} / \mathrm{ml})$, transferrin $(5 \mu \mathrm{g} / \mathrm{ml})$, sodium selenite $(5 \mu \mathrm{ng} / \mathrm{ml})$ (insulin-transferrin-sodium selenite media supplement), gentamycin $(50 \mu \mathrm{g} / \mathrm{ml})$, and puromycin (4 $\mu \mathrm{g} / \mathrm{ml})$ (Perrière et al., 2005) (RBEC medium I) at $37^{\circ} \mathrm{C}$ under a humidified atmosphere of $5 \% \mathrm{CO}_{2} / 95 \%$ air. After 2 days, the medium was changed to RBEC medium II, which contained all the components of RBEC medium except puromycin (Day 2, Fig. 1).

When the cultures reached $80 \%$ confluency (Day 4), the purified endothelial cells were subcultured by a brief treatment with a trypsin $(0.05 \% \mathrm{w} / \mathrm{v})$-EDTA $(0.02 \% \mathrm{w} / \mathrm{v})$ solution, and an in vitro BBB model was constructed with Transwell ${ }^{\circledR}$ (Corning Incorporated Life Sciences, Tewksbury, MA, USA) inserts in 12-well culture plates. Endothelial cells $\left(1.5 \times 10^{5}\right.$ cells $\left./ \mathrm{cm}^{2}\right)$ were seeded on the upper side of the collagenand fibronectin-coated polyester membranes $\left(0.4-\mu \mathrm{m}\right.$ pore size) of Transwell ${ }^{\circledR}$ inserts. This in vitro BBB model was maintained in RBEC medium II for 1 day, and on the next day the medium was changed to serum-free RBEC medium II containing $500 \mathrm{nM}$ hydrocortisone (Hoheisel et al., 1998) (Day 5, Fig. 1). Under these conditions, the in vitro BBB model was established within 3 days after plating the cells. Experiments with HGF were carried out on Day 7 (Fig. 1).

Human umbilical vein endothelial cells (HUVEC) and human dermal microvascular endothelial cells (HMVEC)

HUVEC and HMVEC were obtained from Lonza (Walkersville, MD, USA). Cells were cultured in endothelial cell growth medium (Lonza) containing 5\% fetal bovine serum. They were grown in $75-\mathrm{cm}^{2}$ tissue culture flasks (Corning) at $37^{\circ} \mathrm{C}$ with $5 \% \mathrm{CO}_{2}$ in humidified air. The culture medium was changed three times a week until confluency (5-7 days). Confluent monolayers, detached with a trypsin (0.05\% wt/vol)-EDTA 
$(0.02 \% \mathrm{wt} / \mathrm{vol})$ solution, were subcultured in the medium to supply the experiments. HMVEC and HUVEC $\left(1.5 \times 10^{5}\right.$ cells $\left./ \mathrm{cm}^{2}\right)$ were cultured on 12-well Transwell ${ }^{\circledR}$ collagen and fibronectin-coated polyester membranes (0.4- $\mu$ m pore size) (Fig. 1).

\section{HGF treatment}

In our preliminary functional experiments, RBEC were exposed to HGF (100 ng/mL) in the luminal (upper) or abluminal side (lower compartment). TEER in RBEC was increased by addition into either the luminal or abluminal side. Therefore, HGF receptor seems to have been expressed on both the luminal and abluminal side.

Thereafter, three doses of HGF (10, 100, and $500 \mathrm{ng} / \mathrm{ml})$ were administered into both the luminal and abluminal side of the Transwell ${ }^{\circledR}$ inserts. At 3 and $6 \mathrm{~h}$ after HGF administration to RBEC, barrier integrity was evaluated. Comparisons of the effects of HGF on RBEC, HUVEC, and HMVEC were conducted by treatment with $100 \mathrm{ng} / \mathrm{ml}$ of HGF for 6 h. Goat polyclonal anti-mouse HGF receptor antibody (Gentex, Irvine, CA, USA) was used to neutralize the c-Met-HGF interaction. No notable changes in cell viabilities were determined by a Cell Counting Kit-8 (Dojindo, Kumamoto, Japan) in HGF-treated RBEC, HUVEC, and HMVEC for up to $6 \mathrm{~h}$ compared to the control group.

\section{Evaluation of barrier integrity}

Transendothelial electrical resistance (TEER)

TEER, mainly reflecting the flux of sodium ions through the TJs of endothelial cell layers in culture, was measured using an EVOM resistance meter (World Precision 
Instruments, Sarasota, FL, USA). The extracellular matrix-treated Transwell ${ }^{\circledR}$ inserts were placed in a 12-well plate containing culture medium and then were used to measure the background resistance. The resistance measurements of these blank filters were then subtracted from those of filters with cells. The values are shown as $\Omega \times \mathrm{cm}^{2}$ based on culture inserts.

\section{Transendothelial permeability}

The flux of sodium fluorescein (Na-F) and Evans blue-albumin (EBA) across the endothelial monolayer was determined as previously described (Nakagawa et al. 2007; Horai et al. 2013). Na-F and EBA were used for permeability markers of small molecule and large molecule, respectively. Cell culture inserts were transferred to 12 -well plates containing $1.5 \mathrm{ml}$ assay buffer (136 mM NaCl, $0.9 \mathrm{mM} \mathrm{CaCl}_{2}, 0.5 \mathrm{mM} \mathrm{MgCl}$, $2.7 \mathrm{mM}$ $\mathrm{KCl}, 1.5 \mathrm{mM} \mathrm{KH}_{2} \mathrm{PO}_{4}, 10 \mathrm{mM} \mathrm{NaH} \mathrm{PO}_{4}, 25 \mathrm{mM}$ glucose, and $10 \mathrm{mM}$ HEPES, pH 7.4) in the basolateral or lower compartments. In the inserts, the culture medium was replaced by $0.5 \mathrm{ml}$ buffer containing $10 \mu \mathrm{g} / \mathrm{ml} \mathrm{Na}-\mathrm{F}$ (MW $376 \mathrm{Da}$ ) and $165 \mu \mathrm{g} / \mathrm{mL}$ EBA (MW $67 \mathrm{kDa}$ ). The inserts were transferred at 20, 40, and 60 min to new wells containing assay buffer. The emission of Na-F was measured at $535 \mathrm{~nm}$ (Wallac 1420 ARVO Multilabel Counter, Perkin Elmer, Waltham, MA, USA; excitation: $485 \mathrm{~nm}$ ), while the absorbance of EBA was measured at $595 \mathrm{~nm}$. The permeabilities of Na-F and EBA were used as indexes of paracellular and transcellular transport, respectively (Deli et al. 2005; Nakagawa et al. 2007). The transendothelial permeability coefficient (Pe) was calculated as previously described (Deli et al., 2005). Cleared volume was calculated from the concentration (C) of the tracer in the abluminal and luminal 
compartments and the volume $(\mathrm{V})$ of the abluminal compartment $(0.5 \mathrm{ml})$ by the following equation: Cleared volume $(\mu \mathrm{l})=[\mathrm{C}]_{\text {abluminal }} \times \mathrm{V}_{\text {abluminal }} /[\mathrm{C}]_{\text {luminal. }}$. The average cleared volume was plotted vs. time, and the permeability $\times$ surface area product value for an endothelial monolayer $\left(\mathrm{PS}_{\mathrm{e}}\right)$ was calculated by the following formula: $1 / \mathrm{PS}_{\mathrm{app}}=$ 1/PS $\mathrm{Pmbrane}+1 / \mathrm{PS}_{\mathrm{e}}$. $\mathrm{PS}$ e divided by the surface area $\left(1 \mathrm{~cm}^{2}\right)$ generated the endothelial permeability coefficient (Pe; in $\left.10^{-6} \mathrm{~cm} / \mathrm{s}\right)$.

\section{Immunocytochemistry}

Following treatment with $100 \mathrm{ng} / \mathrm{ml}$ HGF for $6 \mathrm{~h}$, cells were fixed in 3\% paraformaldehyde for $10 \mathrm{~min}$ and permeabilized with $0.1 \%$ Triton-X 100 for $10 \mathrm{~min}$. After washing with phosphate buffered saline (PBS) and blocking with $3 \%$ bovine serum albumin (BSA) in PBS for 30 min, samples were incubated overnight at $4^{\circ} \mathrm{C}$ with anti-claudin-5, occludin, ZO-1 (Invitrogen, Carlsbad, CA, USA), or VE-cadherin (Santa Cruz Biotechnology, Paso Robles, CA, USA) antibodies. All antibodies were diluted 1:100 in PBS containing 0.1\% BSA. The cells were rinsed with PBS and incubated for 1 $\mathrm{h}$ at room temperature with the appropriate secondary antibodies labeled with Alexa Fluor 488 (Invitrogen). To observe cytoskeletal F-actin networks, samples were incubated with Alexa Fluor ${ }^{\circledR} 546$ phalloidin (Invitrogen) at a dilution of 1:400 for 30 min at $37^{\circ} \mathrm{C}$. All samples were examined using a laser-scanning confocal microscope (LSM 5 PASCAL, Carl Zeiss).

Western blot analysis 
Cells were harvested by scraping in CelLytic ${ }^{\mathrm{TM}} \mathrm{M}$ cell lysis reagent supplemented with proteinase inhibitor cocktail (Sigma). Lysates were centrifuged at $12,000 \times g$ for 5 min at $4^{\circ} \mathrm{C}$, supernatants were collected, and protein concentrations were determined with the BCA protein assay reagent (Pierce, Rockford, IL, USA). The samples were mixed with $4 \times$ Laemmli sample buffer and heated at $95^{\circ} \mathrm{C}$ for $5 \mathrm{~min}$. An equal amount of protein for each sample was separated by SDS-PAGE and transferred onto Hybond $^{\mathrm{TM}}$-P (Amersham, Buckinghamshire, UK). Nonspecific binding was blocked with Perfect-Block (MoBiTec GmbH, Germany) (1\% w/v) in Tris-buffered saline (TBS; 25 mM Tris, 150 mM NaCl, 2 mM KCl, pH 7.4) containing 0.1\% Tween-20. Antibodies were used in dilutions of 1:5000 (claudin-5, occludin, and ZO-1), 1:1000 (c-Met, Cell Signaling Technology, Danvers, MA USA), and 1:10,000 ( $\beta$-actin) in blocking solution to incubate blots for $1 \mathrm{~h}$ at room temperature. Peroxidase-conjugated anti-mouse and anti-rabbit immunoglobulin (GE Healthcare, UK) were used as secondary antibodies. Blots were washed three times with TBS between incubations. Immunoreactive bands were identified using the SuperSignal West Femto Maximum Sensitivity Substrate (Pierce), and detected by a FluorChem SP Imaging System (Alpha Innotech Corp., San Leandro, CA, USA).

\section{RT-PCR analysis}

For total RNA extraction, RBEC were cultured in 3.5-mm plastic dishes coated with collagen type IV and fibronectin. Total RNA was isolated with an RNeasy Mini Kit (Qiagen, Hilden, Germany) according to the manufacturer's instructions. First strand cDNA was synthesized from $1 \mu \mathrm{g}$ total RNA with the Reverse Transcription System 
(Promega, Fitchburg, WI, USA). Polymerase chain reaction (PCR) fragments for c-Met were amplified using the following primer pairs: sense 5’-CCGCGATGAGTGAGCACTTC-3’ (20-mer), antisense 5'-TGGTCGGGTGGATTTCAG AG-3' (20-mer). PCR was performed in a final volume of $20 \mu \mathrm{l}$ containing $0.5 \mu \mathrm{l}$ of template cDNA, $1.6 \mu \mathrm{l}$ of dNTP mixture, $2 \mu \mathrm{l}$ of 10× PCR buffer, 0.5 unit of Takara Taq ${ }^{\mathrm{TM}}$ Hot Start Version polymerase (Takara Bio, Inc., Shiga, Japan), and $1 \mu \mathrm{M}$ of each primer, using a PCR Express II thermal cycler (Thermo Electron Corp., Waltham, MA, USA). PCR was performed with 27 cycles of denaturation at $98^{\circ} \mathrm{C}$ for $10 \mathrm{~s}$, annealing at $51^{\circ} \mathrm{C}$ for $30 \mathrm{~s}$, and extension at $72^{\circ} \mathrm{C}$ for $15 \mathrm{~s}$. PCR products were separated by electrophoresis on $1.5 \%$ agarose gels, stained with ethidium bromide, and visualized using FluorChem ${ }^{\mathrm{TM}}$ SP (Alpha Innotech).

Statistical analysis

All data were expressed as the mean \pm standard error of the mean (SEM). The values were compared using an analysis of variance (ANOVA) followed by the Bonferroni-Dunn test. A $P$-value of less than 0.05 was considered to be statistically significant.

\section{Results}

Effect of HGF on barrier integrity in RBEC

TEER in our monolayer model of cultured RBEC was more than $150 \Omega \times \mathrm{cm}^{2}$ (the 
control value at 0 min was $175 \pm 4.3 \Omega \times \mathrm{cm}^{2}, \mathrm{n}=12$, Fig. $2 \mathrm{~A}$ ). To examine whether HGF affected the barrier integrity of RBEC, TEER and paracellular permeability of sodium fluorescein (Na-F, MW 376) were measured. At concentrations of 10, 100, and 500 ng/ml, a 3 h treatment with HGF significantly elevated TEER in RBEC to $115.5 \%$, $116.7 \%$, or $122.1 \%$ of the control, respectively. The increase was maintained for at least $6 \mathrm{~h}$ after HGF treatment (Fig. 2A). HGF also affected the paracellular permeability of $\mathrm{Na}-\mathrm{F}$, a small water-soluble marker, across the RBEC monolayer at $6 \mathrm{~h}$ after treatment with HGF (Fig. 2B). HGF treatments of 100 or $500 \mathrm{ng} / \mathrm{ml}$ significantly decreased the permeability of $\mathrm{Na}-\mathrm{F}$ in RBEC to $56.3 \%$ or $55.2 \%$ of the control, respectively (Pe control value was $4.5 \pm 0.3 \times 10^{-6} \mathrm{~cm} / \mathrm{s}$ ). We also determined the effect of HGF on the permeability of Evans blue albumin (EBA, MW $67 \mathrm{kDa}$ ), an index of transcellular permeability. EBA permeability in RBEC monolayers was decreased to $72.2 \%$ of the control at $6 \mathrm{~h}$ by HGF treatment at a concentration of $500 \mathrm{ng} / \mathrm{ml}$ (Pe control value was $\left.0.16 \pm 0.01 \times 10^{-6} \mathrm{~cm} / \mathrm{s}\right)($ Fig. $2 \mathrm{C})$. Thus, HGF strengthened the BBB barrier properties in RBEC.

Expression of c-Met in RBEC and effect of anti-c-Met antibody on HGF-induced enhancement of TJ functions in RBEC

We examined the expression of an HGF receptor on cultured RBEC by western blotting and RT-PCR. c-Met, a high affinity tyrosine kinase receptor for HGF, is a disulfide-linked heterodimer made of $45 \mathrm{kDa} \alpha$ - and $145 \mathrm{kDa} \beta$-subunits. Western blot analysis indicated that c-Met was detected at $145 \mathrm{kDa}$, similar to what is observed in HeLa cells (Fig. 3A). RT-PCR produced a product of $369 \mathrm{bp}$, which corresponds to the 
expected amplicon size for c-Met (Fig. 3A). We were thus able to detect the HGF receptor c-Met in RBEC. Furthermore, to examine whether the effect of HGF on barrier functions is related to the c-Met-HGF interaction, we examined the effect of c-Met neutralizing antibody on RBEC. The effect of HGF on elevated TEER was prevented by adding $10 \mu \mathrm{g} / \mathrm{ml}$ of c-Met neutralizing antibody for $6 \mathrm{~h}$ (Fig. 3B). Consistent with the data on TEER, adding c-Met neutralizing antibody to both luminal and abluminal chambers completely blocked the effect of HGF on Na-F permeability in RBEC (Fig. 3C).

Effects of HGF on barrier integrity in HMVEC and HUVEC

Several reports have demonstrated that exposure to HGF can disrupt endothelial/epithelial integrity (Jiang et al., 1999, Martin et al., 2002). Therefore, in parallel experiments using peripheral derived endothelial cells, we examined the effects of HGF on HMVEC and HUVEC derived from dermal microvessels and umbilical veins, respectively. A 9\% decrease in TEER for HMVEC was observed following treatment with $100 \mathrm{ng} / \mathrm{ml}$ HGF for 6 h. However, there were no changes in TEER for HUVEC (Fig. 4A). Na-F and EBA permeabilities in HMVEC and HUVEC were examined. HGF induced a significant increase of Na-F permeability in HMVEC and HUVEC to $153.6 \%$ or $115.8 \%$ of the control, respectively (Fig. 4B). EBA permeability was also increased in both HMVEC and HUVEC to $153.5 \%$ or $137.1 \%$ of the control, respectively (Fig. 4C).

Effect of HGF on ZO-1 and F-actin staining in vascular endothelial cells 
To investigate whether the regulation of barrier functions induced by HGF in the three types of endothelial cells is related to the TJ protein ZO-1 or the cytoskeletal F-actin network, we performed immunostaining. ZO-1 exhibited discontinuous and linear staining localized in the margin of the cell border between RBEC (Fig. 5B); however, the immunostaining became clearer and sharper in HGF-treated $(100 \mathrm{ng} / \mathrm{mL}$ for 6 h) RBEC (Fig. 5A). In HMVEC, zipper-like staining with branching points at the cell-cell contacts was observed in HGF-treated cells, with the appearance of the TJ protein resembling a prickly-leaf shape (Fig. 5C). No notable change in ZO-1 staining was observed in HGF-treated HUVEC (Fig. 5E) compared to the control (Fig. 5F). The blurry and non-linear appearance of ZO-1 observed in HUVEC is consistent with the weakness of the barrier properties measured by TEER (Fig. 4A). Control RBEC had numerous cytoplasmic actin stress fibers (Fig. 5H). The F-actin appearance of stress fibers decreased, and a smooth localization of F-actin bundles at the cell border was detected in HGF-treated RBEC (Fig. 5G). Conversely, in HMVEC and HUVEC, HGF reduced cortical actin bands and increased stress fiber density, characterized by a jagged, zigzag appearance (Fig. 5I and K). Thus, similar to ZO-1 staining, immunocytochemical analysis revealed that there was reorganization of the actin cytoskeleton in HGF-treated RBEC.

Effect of HGF on TJ proteins and VE-cadherin staining in RBEC

To examine the expression of claudin-5, occludin, and VE-cadherin as additional cell adhesion proteins in HGF-treated RBEC, we performed immunostaining. We could not 
detect differences in claudin-5, occludin, or VE-cadherin staining, or morphological changes, between control and HGF-treated RBEC (Fig. 6).

Effect of HGF on protein levels of cell adhesion proteins

Changes in TJ and AJ protein levels in HGF-treated RBEC were investigated by western blot analysis. As shown in Figure 7, there were no differences in claudin-5 or occludin proteins levels between control and HGF-treated RBEC. In contrast, HGF increased the protein level of ZO-1 and VE-cadherin (Fig. 7).

\section{Discussion}

The BBB plays an important role as an interface between the blood and brain tissues. As disruption of the $\mathrm{BBB}$ evokes brain edema formation and neuronal damage, the strengthening of BBB integrity has a crucial role in protection against the development of neurological disorders. In the present study, we found that HGF improved BBB integrity via rearrangement of actin cytoskeletons and upregulation of ZO-1 and VE-cadherin proteins. This finding implies that HGF may act as a BBB protective drug for CNS disorders.

The multifunctional protein HGF and its receptor c-Met are present in developing and adult brains (Honda et al., 1995; Achim et al., 1997). In agreement with these observations, our cultured RBEC expressed c-Met mRNA and protein. Although there have been several studies that have examined the effects of HGF on barrier function in endothelial/epithelial cells (Nusrat et al., 1994; Jiang et al., 1999; Martin et al., 2002, 2004; Pollack et al., 2004; Singleton et al., 2007), there is no report that examines the 
direct effect of HGF on the barrier function of brain capillary endothelial cells in normal culture conditions. We observed that HGF worked on RBEC to elevate TEER and decrease permeability in a dose- and time-dependent manner. As this effect was inhibited by anti-cMet neutralizing antibody, it seems that the binding of HGF to c-Met activates intracellular signaling to alter the barrier function in RBEC. As TEER and the permeability of endothelial cells reflect TJ function (Deli et al., 2005), it has been thought that the target of HGF is the TJs. To examine the effect of HGF on TJ proteins, we analyzed the expression of TJ proteins by immunostaining and western blotting. When immunostaining for claudin-5, occludin, and ZO-1, the morphological pattern of ZO-1 was changed to a continuous and smooth pattern by HGF treatment. Taken together with western blotting analysis, it seems that the histological improvement in ZO-1 immunostaining is associated with increasing the ZO-1 protein level. No clear changes in claudin-5 or occludin were observed by either immunostaining or western blotting after HGF treatment. Similar to previous reports showing that HGF affects the assembly of TJ proteins (Balkovetz et al., 1997; Pollack et al., 2004), our observations indicate that HGF enhances TJ function in RBEC through alteration of ZO-1. However, since transmembrane proteins claudin-5 and occludin, the main component proteins of TJ strands, play crucial roles in TJ function (Furuse and Tsukita, 2006; Abbott et al., 2010), HGF may influence claudin-5 and occludin without a change in protein level. Recent studies have indicated that barrier tightness of the BBB seems to be related to the phosphorylation of claudin-5 and occludin (Ishizaki et al., 2003; Kago et al., 2006; Soma et al., 2007; Yamamoto et al., 2008; Dörfel and Huber, 2012). Although we could not use proper antibodies to detect the phosphorylated claudin-5 and occludin, whether HGF affects the phosphorylation of claudin-5 and occludin needs to be considered. 
In addition to TJs, AJs and the cytoskeletal F-actin network also play important roles in the regulation of barrier function in endothelial cells (Bogatcheva and Verin, 2008; Dejana et al., 2008; Vandenbroucke et al., 2008). Furthermore, transmembrane proteins in TJs and AJs are linked to the actin cytoskeleton by intracellular accessory proteins that can interact with each other. To examine whether HGF affected AJs and the F-actin network, HGF was used to treat RBEC. We found that HGF induced F-actin rearrangement and increased the expression of VE-cadherin in RBEC. The rearrangement of cytoskeletal actin fibers is an important factor that affects barrier function of endothelial cells (Lai et al., 2005; Vandenbroucke et al., 2008; Spindler et al., 2011). Accumulating evidence suggests that HGF stimulates multiple signaling pathways, such as small GTPase Rac, MAP, PKC, PI3-kinase, and its downstream effector GSK-3 $\beta$ (Liu et al., 2002; Trusolino et al., 2010). cAMP/PKA and cAMP/Epac1/Rap1 signaling-mediated Rac1 activations influence actin rearrangement. In fact, Birukova et al. (2007) reported that HGF attenuates thrombin-induced endothelial permeability by the Rac pathway. In addition, Liu et al. (2002) reported that HGF enhances the barrier function of endothelial cells and induces rearrangement of cortical cytoskeletons in pulmonary artery endothelial cells through the PI3-kinase/GSK-3 $\beta$ pathway. Thus, in the present study, these pathways may be involved in HGF-induced rearrangement of F-actin in RBEC. McGuire et al. (2011) indicated that pericyte-derived sphingosine 1-phosphate $\left(\mathrm{S}_{1} \mathrm{P}\right)$, a bioactive sphingolipid metabolite, increases the expression of VE-cadherin in retinal endothelial cells. Similar to intracellular signaling activated by $\mathrm{HGF}, \mathrm{S}_{1} \mathrm{P}$ activates several possible downstream signaling molecules including Rac, ERK, and PI3 kinase. Further studies are needed to determine whether these signaling pathways are associated with regulation of the 
expression of VE-cadherin in HGF-treated RBEC.

In the present study, we compared the effects of HGF in both brain and peripheral endothelial cells. In contrast to brain derived endothelial cells, our studies indicated that HGF decreased the barrier function of the endothelial cells derived from peripheral tissue. Our data indicated that HGF affected the distribution of ZO-1 and cytoskeletal actin in HMVEC. Though we could not detect any effects of HGF on claudin-5 and occludin in HMVEC and HUVEC in the present preliminary study, further studies are needed.

Although we could not ascertain the mechanism of these outcomes, it seems that treatment of endothelial/epithelial cells with HGF has different effects on the barrier function depending on cell type, cell viability, and so on. However, the different outcomes may be related to the origin of the endothelial cells. Brain capillary endothelial cells have several characteristic differences compared with peripheral endothelial cells, including high electrical resistance, the lack of pinocytosis and fenestrae, restricted passage of solutes and cells to the brain, the presence of transendothelial transport pathways, and expression of a variety of transporters (Ohtsuki and Terasaki, 2007; Neuwelt et al., 2008. Abbott et al., 2010). In addition to these BBB properties, Daneman et al. (2010) indicated that numerous signaling cascades and metabolic pathways in brain endothelial cells are also different from peripheral endothelial cells. Several reports have shown that different results depend on the cellular origin. The TEER in response to astrocytic input can differ between brain and peripheral endothelia (Dehouk et al., 1990; Cecchelli et al., 2007). Furthermore, there are also clear differences in the behavior toward macromolecules, such as low-density lipoproteins (LDLs), between brain endothelial cells and peripheral endothelium 
(Dehouck et al., 1994). Spindler et al. (2011) indicated that cAMP signaling is barrier-protective via Rac1 in microvascular endothelial cells, but not in macrovascular endothelial cells. Our observation may represent an intrinsic difference between brain and peripheral endothelial cells. Of course, the differences observed in the present study may also have other causes, such as species differences or culture conditions. More studies to characterize the signaling induced by HGF are required to fully understand these observations.

In summary, we report that HGF acts directly on brain capillary endothelial cells, improves the function of TJs and AJs of the $\mathrm{BBB}$, and induces actin rearrangement. Our present observations support previous studies showing that HGF decreases cerebral ischemia-induced leakage of albumin passing through brain capillary endothelial cells, and attenuates learning dysfunction in a rat ischemia model in vivo (Date et al., 2004, 2006). Improving BBB function under brain injury prevents the penetration of neurotoxic factors into brain parenchyma and leads to neuronal survival. HGF may act as a neurotrophic factor and BBB-protective factor in vivo. Our present study indicates the therapeutic significance of HGF in protecting the BBB under CNS damage.

\section{Acknowledgments}

We thank Yasuko Yamashita for her critical review of the manuscript and outstanding professional guidance. This work was supported by a Grant-in-Aid for Young Scientists (B) (10019095) from the Ministry of Education, Culture, Sports, Science and Technology, Japan. 


\section{References}

Abbott, N.J., Patabendige, A.A., Dolman, D.E., Yusof, S.R., Begley, D.J., 2010. Structure and function of the blood-brain barrier. Neurobiol. Dis. 37, 13-25

Achim, C.L., Katyal, S., Wiley, C.A., Shiratori, M., Wang, G., Oshika, E., Petersen, B.E., Li, J.M., Michalopoulos, G.K., 1997. Expression of HGF and cMet in the developing and adult brain. Brain Res. Dev. Brain. Res. 102, 299-303.

Aird, W.C., 2007. Phenotypic heterogeneity of the endothelium: I. Structure, function, and mechanisms. Circ. Res. 100, 158-173.

Balkovetz, D.F., Pollack, AL., Mostov, K.E., 1997. Hepatocyte growth factor alters the polarity of Madin-Darby canine kidney cell monolayers. J. Biol. Chem. 272, 3471-3477.

Birukova, A.A., Alekseeva, E., Mikaelyan, A., Birukov, KG., 2007. HGF attenuates thrombin-induced endothelial permeability by Tiam1-mediated activation of the Rac pathway and by Tiam1/Rac-dependent inhibition of the Rho pathway. FASEB. J. 21, 2776-2786.

Bogatcheva, N.V., Verin, A.D., 2008. The role of cytoskeleton in the regulation of vascular endothelial barrier function. Microvasc. Res. 76, 202-207.

Cecchelli, R., Berezowski, V., Lundquist, S., Culot, M., Renftel, M., Dehouck, M.P., Fenart, L. 2007. Modeling of the blood-brain barrier in drug discovery and development. Nat. Rev. Drug. Discov. 6, 650-661.

Daneman, R., Zhou, L., Agalliu, D., Cahoy, J.D., Kaushal, A., Barres, B.A., 2010. The mouse blood-brain barrier transcriptome: a new resource for understanding the development and function of brain endothelial cells. PLoS One 5, e13741. 
Date, I., Takagi, N., Takagi, K., Kago, T., Matsumoto, K., Nakamura, T., Takeo, S., 2004. Hepatocyte growth factor attenuates cerebral ischemia-induced learning dysfunction. Biochem. Biophys. Res. Commun. 319, 1152-1158.

Date, I., Takagi, N., Takagi, K., Tanonaka, K., Funakoshi, H., Matsumoto, K., Nakamura, T., Takeo, S., 2006. Hepatocyte growth factor attenuates cerebral ischemia-induced increase in permeability of the blood-brain barrier and decreases in expression of tight junctional proteins in cerebral vessels. Neurosci. Lett. 407, 141-145.

Dehouck, M.P., Meresse, S., Delorme, P., Fruchart, J.C., Cecchelli, R., 1990. An easier, reproducible and mass production method to study the blood-brain barrier in vitro. J. Neurochem. 54, 1798-1801.

Dehouck, B., Dehouck, M.P., Fruchart, J.C., Cecchelli, R., 1994. Upregulation of the low density lipoprotein receptor at the blood-brain barrier: Intercommunications between brain capillary endothelial cells and astrocytes. J. Cell. Biol. 126, 465-473.

Dejana, E., Orsenigo, F., Lampugnani, M.G., 2008. The role of adherens junctions and VE-cadherin in the control of vascular permeability. J. Cell Sci. 121, 2115-2122.

Deli, M.A., Ábrahám, C.S., Kataoka, Y., Niwa, M., 2005. Permeability studies on in vitro blood-brain barrier models: physiology, pathology and pharmacology. Cell Mol. Neurobiol. 25, 59-127.

Dörfel, M.J., Huber, O., 2012. A phosphorylation hotspot within the occludin C-terminal domain. Ann. N. Y. Acad. Sci. 1257, 38-44.

Furuse, M., Tsukita, S., 2006. Claudins in occluding junctions of humans and flies. Trends. Cell. Biol. 16, 181-188. 
Giepmans, B.N., van Ijzendoorn, S.C., 2009. Epithelial cell-cell junctions and plasma membrane domains. Biochim. Biophys. Acta. 1788, 820-831.

Hermann, D.M., Elali, A., 2012. The abluminal endothelial membrane in neurovascular remodeling in health and disease. Sci. Signal. 5, re4.

Hoheisel, D., Nitz, T., Franke, H., Wegener, J., Hakvoort, A., Tilling, T., Galla, H.J., 1998. Hydrocortisone reinforces the blood-brain barrier properties in a serum free cell culture system. Biochem. Biophys. Res. Commun. 244, 312-316.

Honda, S., Kagoshima, M., Wanaka, A., Tohyama, M., Matsumoto, K., Nakamura, T., 1995. Localization and functional coupling of HGF and c-Met/HGF receptor in rat brain: implication as neurotrophic factor. Brain Res. Mol. Brain Res. 32, 197-210.

Horai, S., Nakagawa, S., Tanaka, K., Morofuji, Y., Couraud, P.O., Deli, M.A., Ozawa, H., Niwa, M., 2013. Cilostazol strengthens barrier integrity in brain endothelial cells. Cell. Mol. Neurobiol. 33, 291-307.

Ishizaki, T., Chiba, H., Kojima, T., Fujibe, M., Soma, T., Miyajima, H., Nagasawa, K., Wada, I., Sawada, N., 2003. Cyclic AMP induces phsophorylation of claudin-5 gene in blood-brain barrier endothelial cells via protein-kinase A-dependent and -independent pathway. Exp. Cell Res. 290, 275-288.

Jiang, W.G., Martin, T.A., Matsumoto, K., Nakamura, T., Mansel, R.E., 1999. Hepatocyte growth factor/scatter factor decreases the expression of occludin and transendothelial resistance (TER) and increases paracellular permeability in human vascular endothelial cells. J, Cell Physiol. 181, 319-329.

Kago, T., Takagi, N., Date, I., Takenaga, Y., Takagi, K., Takeo, S., 2006. Cerebral ischemia enhances tyrosine phosphorylation of occludin in brain capillaries. 
Biochem. Biophys. Res. Commun. 339, 1197-1203.

Lai, C.H., Kuo, K.H., Leo, J.M., 2005. Critical role of actin in modulating BBB permeability. Brain Res. Brain Res. Rev. 50, 7-13.

Liu, F., Schaphorst, K.L., Verin, A.D., Jacobs, K., Birukova, A., Day, R.M., Bogatcheva, N., Bottaro, D.P., Garcia, J.G., 2002. Hepatocyte growth factor enhances endothelial cell barrier function and cortical cytoskeletal rearrangement: potential role of glycogen synthase kinase-3beta. FASEB. J. 16, 950-962.

Martin, T.A., Mansel, R.E., Jiang, W.G., 2002. Antagonistic effect of NK4 on HGF/SF induced changes in the transendothelial resistance (TER) and paracellular permeability of human vascular endothelial cells. J. Cell Physiol. 192, 268-275.

Martin, T.A., Watkins, G., Mansel, R.E., Jiang, W.G., 2004. Hepatocyte growth factor disrupts tight junctions in human breast cancer cells. Cell Biol. Int. 28, 361-371.

Matsumoto, K., Nakamura, T., 1996. Emerging multipotent aspects of hepatocyte growth factor. J. Biochem. 119, 591-600.

Maulik, G., Shrikhande, A., Kijima, T., Ma, P.C., Morrison, P.T., Salgia, R., 2002. Role of the hepatocyte growth factor receptor, c-Met, in oncogenesis and potential for therapeutic inhibition. Cytokine Growth Factor Rev. 13, 41-59.

McGuire, P.G., Rangasamy, S., Maestas, J., Das, A., 2011. Pericyte-derived sphingosine 1-phosphate induces the expression of adhesion proteins and modulates the retinal endothelial cell barrier. Arterioscler. Thromb. Vasc. Biol. 31, e107-115.

Miyazawa, T., Matsumoto, K., Ohmichi, H., Katoh, H., Yamashima, T., Nakamura, T., 1998. Protection of hippocampal neurons from ischemia-induced delayed neuronal death by hepatocyte growth factor: a novel neurotrophic factor. J. 
Cereb. Blood Flow Metab. 18, 345-348.

Nakagawa, S., Deli, M.A., Nakao, S., Honda, M., Hayashi, K., Nakaoke, R., Kataoka, Y., Niwa, M., 2007. Pericytes from brain microvessels strengthen the barrier integrity in primary cultures of rat brain endothelial cells. Cell. Mol. Neurobiol. 27, 687-694.

Nakagawa, S., Deli, M.A., Kawaguchi, H., Shimizudani, T., Shimono, T., Kittel, A., Tanaka, K., Niwa, M., 2009. A new blood-brain barrier model using primary rat brain endothelial cells, pericytes and astrocytes. Neurochem. Int. 54, 253-263.

Neuwelt, E., Abbott, N.J., Abrey, L., Banks, W.A., Blakley, B., Davis, T., Engelhardt, B., Grammas, P., Nedergaard, M., Nutt, J., Pardridge, W., Rosenberg, G.A., Smith, Q., Drewes, L.R., 2008. Strategies to advance translational research into brain barriers. Lancet Neurol. 7, 84-96.

Nusrat, A., Parkos, C.A., Bacarra, A.E., Godowski, P.J., Delp-Archer, C., Rosen, E.M., Madara, J.L., 1994. Hepatocyte growth factor/scatter factor effects on epithelia. Regulation of intercellular junctions in transformed and nontransformed cell lines, basolateral polarization of c-met receptor in transformed and natural intestinal epithelia, and induction of rapid wound repair in a transformed model epithelium. J. Clin. Invest. 93, 2056-2065.

Ohtsuki, S., Terasaki, T., 2007. Contribution of carrier-mediated transport systems to the blood-brain barrier as a supporting and protecting interface for the brain; importance for CNS drug discovery and development. Pharm. Res. 24, 1745-1758.

Perriere, N., Demeuse, P., Garcia, E., Regina, A., Debray, M., Andreux, J.P., Couvreur, P., Scherrmann, J.M., Temsamani, J., Couraud, P.O., Deli, M.A., Roux, F. 2005. 
Puromycin-based purification of rat brain capillary endothelial cell cultures. Effect on the expression of blood-brain barrier-specific properties. J. Neurochem. 93, 279-289.

Pollack, A.L., Apodaca, G., Mostov, K.E., 2004. Hepatocyte growth factor induces MDCK cell morphogenesis without causing loss of tight junction functional integrity. Am. J. Physiol. Cell Physiol. 286, 482-494.

Quaegebeur, A., Lange, C., Carmeliet, P., 2011. The neurovascular link in health and disease: molecular mechanisms and therapeutic implications. Neuron 71, 406-424.

Regan, E.R., Aird, W.C., 2012. Dynamical systems approach to endothelial heterogeneity. Circ. Res. 2012 111, 110-130.

Shimamura, M., Sato, N., Oshima, K., Aoki, M., Kurinami, H., Waguri, S., Uchiyama, Y., Ogihara, T., Kaneda, Y., Morishita, R., 2004. Novel therapeutic strategy to treat brain ischemia: overexpression of hepatocyte growth factor gene reduced ischemic injury without cerebral edema in rat model. Circulation 109, 424-431.

Singleton, P.A., Salgia, R., Moreno-Vinasco, L., Moitra, J., Sammani, S., Mirzapoiazova, T., Garcia, J.G., 2007. CD44 regulates hepatocyte growth factor-mediated vascular integrity. Role of c-Met, Tiam1/Rac1, dynamin 2, and cortactin. J. Biol. Chem. 282, 30643-30657.

Soma, T., Chiba, H., Kato-Mori, Y., Wada, T., Yamashita, T., Kojima, T., Sawada, N., 2004. Thr (207) of claudin-5 is involved in size-selective loosening of the endothelial barrier by cyclic AMP. Exp. Cell Res. 300, 202-212.

Spindler, V., Peter, D., Harms, G.S., Asan, E., Waschke, J., 2011. Ultrastructural analysis reveals cAMP-dependent enhancement of microvascular endothelial barrier 
functions via Rac1-mediated reorganization of intercellular junctions. Am. J. Pathol. 178, 2424-2436.

Trusolino, L., Bertotti, A., Comoglio, PM., 2010. MET signalling: principles and functions in development, organ regeneration and cancer. Nat. Rev. Mol. Cell Biol. 11, 834-48.

Vandenbroucke, E., Mehta, D., Minshall, R., Malik, A.B., 2008. Regulation of endothelial junctional permeability. Ann. N. Y. Acad. Sci. 1123, 134-145.

Yamamoto, M., Ramirez, S.H., Sato, S., Kiyota, T., Cerny, R.L., Kaibuchi, K., Persidsky, Y., Ikezu, T., 2008. Phosphorylation of caludin-5 and occluding by Rho kinase in brain endothelial cells. Am. J. Pathol. 172, 521-533

Zlokovic, B.V., 2008. The blood-brain barrier in health and neurodegenerative disorders. Neuron 57, 178-201 


\section{Figure legends}

Fig. 1. Schematic drawing of the experiments with primary cultures of rat brain capillary endothelial cells (RBEC), human umbilical vein endothelial cells (HUVEC), and human dermal microvascular endothelial cells (HMVEC). RBEC were isolated 4 days before the establishment of the in vitro BBB model. To purify cultures, cells were kept in the presence of puromycin $(4.0 \mu \mathrm{g} / \mathrm{mL})$ for 2 days (RBEC I medium + puromycin). On Day 4, RBEC, HUVEC, and HMVEC were seeded on the top of polyester membranes of 12-well Transwell ${ }^{\circledR}$ inserts. From Day 5, the medium in each model was changed to serum-free medium containing $500 \mathrm{nM}$ hydrocortisone. Experiments were performed on Day 7.

Fig. 2. Effects of hepatocyte growth factor (HGF) on barrier integrity in RBEC. The barrier integrity was assessed by transendothelial electrical resistance (TEER) (A), and the transendothelial permeability $(\mathrm{Pe})$ of the paracellular transport marker sodium fluorescein (Na-F) (B) and the transcellular transport marker Evans blue albumin (EBA) (C) across endothelial monolayers. (A) HGF dose-dependently and time-dependently increased TEER in RBEC. Confluent RBEC cultures were exposed to HGF at concentrations of 10,100 , and $500 \mathrm{ng} / \mathrm{ml}$ for up to $6 \mathrm{~h}$. Significantly higher levels of TEER were detected in RBEC treated with $10 \mathrm{ng} / \mathrm{ml}$ (light gray bar), $100 \mathrm{ng} / \mathrm{ml}$ (dark gray bar), and $500 \mathrm{ng} / \mathrm{ml}$ (black bar) for 3 and $6 \mathrm{~h}$. TEER values are expressed as a percent of the control value. The control value of TEER in RBEC was $175 \pm 4.33 \Omega \times$ $\mathrm{cm}^{2}$ at $0 \mathrm{~h}$. All data are presented as means \pm SEM $(\mathrm{n}=3) .{ }^{*} P<0.05$ and ${ }^{* *} P<0.01$, significant difference from control. ${ }^{\#} P<0.01$, significant difference from $10 \mathrm{ng} / \mathrm{ml} \mathrm{HGF}$. 
(B, C) HGF reduced Na-F and EBA Pe in RBEC. The cells were treated with increasing concentrations of HGF for 6 h. Significantly lower Pe values of Na-F and EBA were detected in RBEC treated with $100 \mathrm{ng} / \mathrm{ml}$ and $500 \mathrm{ng} / \mathrm{ml} \mathrm{HGF}$ for Na-F, and $500 \mathrm{ng} / \mathrm{ml}$ for EBA. Pe values are expressed as a percent of the control value. The control values of Pe for Na-F and EBA were $4.55 \pm 0.32 \times 10^{-6} \mathrm{~cm} / \mathrm{s}$ and $0.16 \pm 0.01 \times 10^{-6} \mathrm{~cm} / \mathrm{s}$, respectively. All data are presented as means \pm SEM $(\mathrm{n}=7) .{ }^{*}<0.05$ and ${ }^{* * P}<0.01$, significant differences from control.

Fig. 3. HGF receptor c-Met expressed on RBEC is related to regulation of TJ function induced by HGF. (A) Expression of c-Met was analyzed by western blot and reverse transcription (RT)-PCR analyses. (A) Expression of c-Met was determined in cell extracts by western blotting. HeLa cells were used as a positive control. Western blotting revealed a band for c-Met at $145 \mathrm{kDa}$ (upper panel). A specific amplicon for rat c-Met (369 bp) was detected by RT-PCR (lower panel). (B, C) Effect of anti-c-Met antibody on HGF-induced enhancement of TJ functions in RBEC. TJ function was assessed by TEER (B) and permeability of Na-F (C) across RBEC monolayers. (B) TEER was significantly elevated in RBEC treated with $100 \mathrm{ng} / \mathrm{ml} \mathrm{HGF}$ for $6 \mathrm{~h}$ (dark-gray column). ${ }^{* *} P<0.01$, significant difference from control. Anti-c-Met antibody completely blocked the HGF-induced increase in TEER (black column). ${ }^{\#} P<$ 0.01, significant difference from anti-cMet $(-)$ HGF (+) group. No change was observed in RBEC treated alone with anti-cMet for $6 \mathrm{~h}$ (light gray column). The TEER values are expressed as a percent of the control value (open column). The control value of TEER in RBEC was $174.5 \pm 12.2 \Omega \times \mathrm{cm}^{2}$. All data are presented as means $\pm \operatorname{SEM}(\mathrm{n}=8)$. (C) Na-F permeability was significantly reduced in RBEC treated with $100 \mathrm{ng} / \mathrm{ml} \mathrm{HGF}$ for 
6 h (dark-gray column). ${ }^{* *} P<0.01$, significant difference from control. Anti-c-Met antibody completely blocked the HGF-induced reduction in Na-F permeability (black column) ${ }^{\#} P<0.05$, significant difference from anti-c-Met antibody $(-)$ HGF $(+)$ group. No change was observed in RBEC treated alone with Anti-c-Met antibody for $6 \mathrm{~h}$ (light gray column). The Pe values are expressed as a percentage of the control value (open column). The control value of Pe in RBEC was $8.01 \pm 0.90 \times 10^{-6} \mathrm{~cm} / \mathrm{s}$. All data are presented as means \pm SEM $(n=8)$.

Fig. 4. Effects of HGF on barrier integrity in HMVEC and HUVEC. The barrier integrity was assessed by TEER (A) and by permeability of Na-F (B) and EBA (C) across endothelial monolayers at $6 \mathrm{~h}$ after treatment with control (open column) and 100 ng/ml HGF (gray column). (A) TEER in HMVEC treated with $100 \mathrm{ng} / \mathrm{ml}$ for $6 \mathrm{~h}$ was significantly decreased. The control value of TEER in HMVEC was $51 \pm 1.15 \Omega \times \mathrm{cm}^{2}$. ${ }^{*} P<0.05$, significant difference from control. No change was observed in HUVEC treated with HGF for $6 \mathrm{~h}$. The control value of TEER in HUVEC was $12 \pm 0.0 \Omega \times \mathrm{cm}^{2}$. (B) Pe values of Na-F in HMVEC and HUVEC treated with $100 \mathrm{ng} / \mathrm{ml}$ HGF were significantly increased. The control values of Pe in HMVEC and HUVEC were $24.9 \pm$ $2.62 \times 10^{-6}$ and $28.1 \pm 1.42 \times 10^{-6}$, respectively. $* P<0.05$, significant difference from control. (C) Pe values of EBA in HMVEC and HUVEC treated with $100 \mathrm{ng} / \mathrm{ml} \mathrm{HGF}$ were significantly increased. The control values of Pe in HMVEC and HUVEC were $0.90 \pm 0.04 \times 10^{-6}$ and $1.34 \pm 0.10 \times 10^{-6}$, respectively. $* P<0.05$, significant difference from control. All data are presented as means \pm SEM $(n=4)$.

Fig. 5. Immunofluorescent staining for TJ protein ZO-1 and cytochemical staining of 
F-actin in RBEC, HMVEC, and HUVEC. Immunostaining of ZO-1 in RBEC (A), HMVEC (C), and HUVEC (E) treated with $100 \mathrm{ng} / \mathrm{ml}$ HGF for $6 \mathrm{~h}$, and in control RBEC (B), HMVEC (D), and HUVEC (F). In RBEC treated with 100 ng/ml HGF, a continuous and smooth pattern of ZO-1 immunostaining was noted compared with the control. Asterisk $(*)$ indicates discontinuous staining on the cell-cell border. In contrast, HGF produced a zipper-like appearance of ZO-1 immunostaining (arrowheads) in HMVEC. There were no significant differences between the images of ZO-1 in HUVEC treated with HGF and in control cells. Cytochemical staining of F-actin in RBEC (G), HMVEC (I), and HUVEC (K) treated with 100 ng/ml HGF, and in control RBEC (H), HMVEC (J), and HUVEC (L). HGF also produced a smooth and sharp bundle of cytoskeletal F-actin along the RBEC border, although control RBEC had numerous cytoplasmic-actin stress fibers. Conversely, in HMVEC and HUVEC, HGF reduced cortical actin bands and increased the stress fiber density. Arrows indicate stress fibers. $\operatorname{Bar}=20 \mu \mathrm{m}$.

Fig. 6. Immunofluorescent staining for TJ proteins claudin-5 and occludin, and for adherens junction (AJ) protein VE-cadherin in RBEC treated with $100 \mathrm{ng} / \mathrm{ml} \mathrm{HGF}$ for 6 h. There were no significant differences between the images of claudin-5 (A, B), occludin (C, D), and VE-cadherin (E, F) in RBEC treated with HGF and in control cells. Bar $=20 \mu \mathrm{m}$.

Fig. 7. Effect of HGF on the expression of TJ and AJ proteins in RBEC. (A) Western blot analyses of ZO-1, claudin-5, occludin, and VE-cadherin were performed after $6 \mathrm{~h}$ of $100 \mathrm{ng} / \mathrm{ml}$ HGF treatment in RBEC. The blots are representative images from three 
separate experiments. (B) Graph represents densitometric measurements from these experiments. The level of expression of each protein was normalized to the corresponding internal control ( $\beta$-actin). HGF increased the expression of ZO-1 and VE-cadherin in RBEC. All data are presented as means \pm SEM ( $=8-11)$. Significantly different from controls at $* P<0.05$ or $* * P<0.01$. 

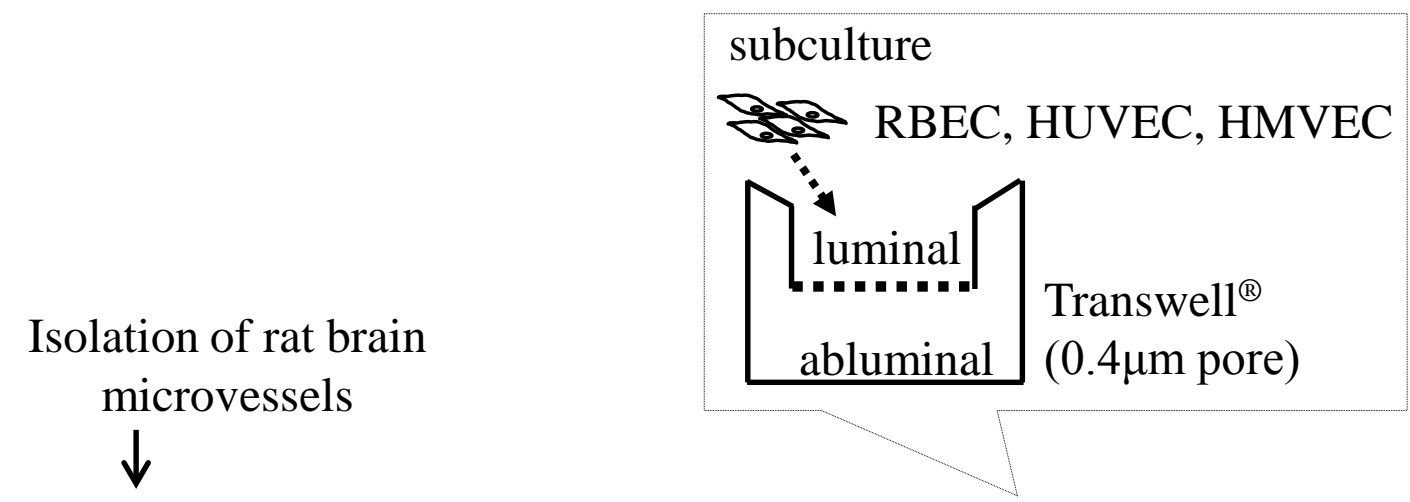

Day 0
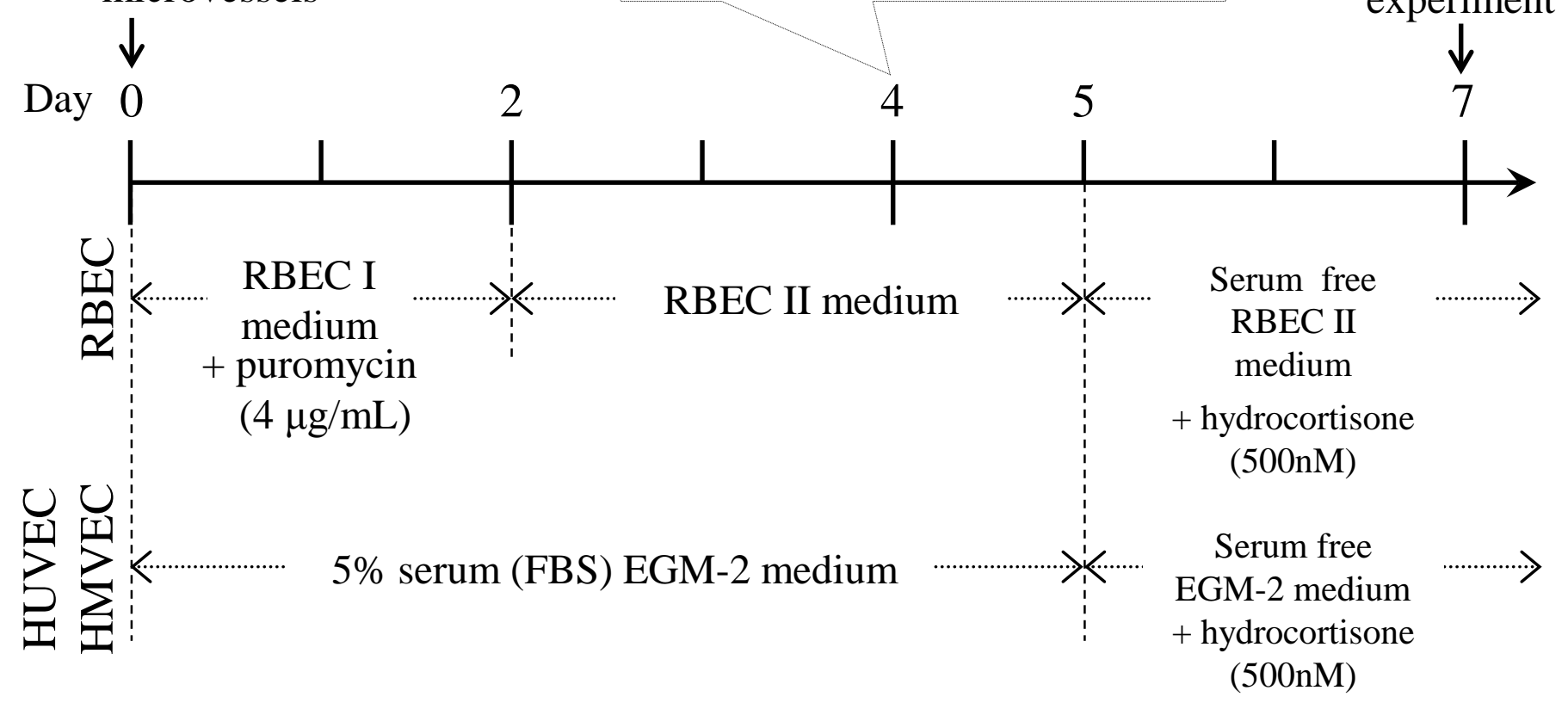

Fig. 1 

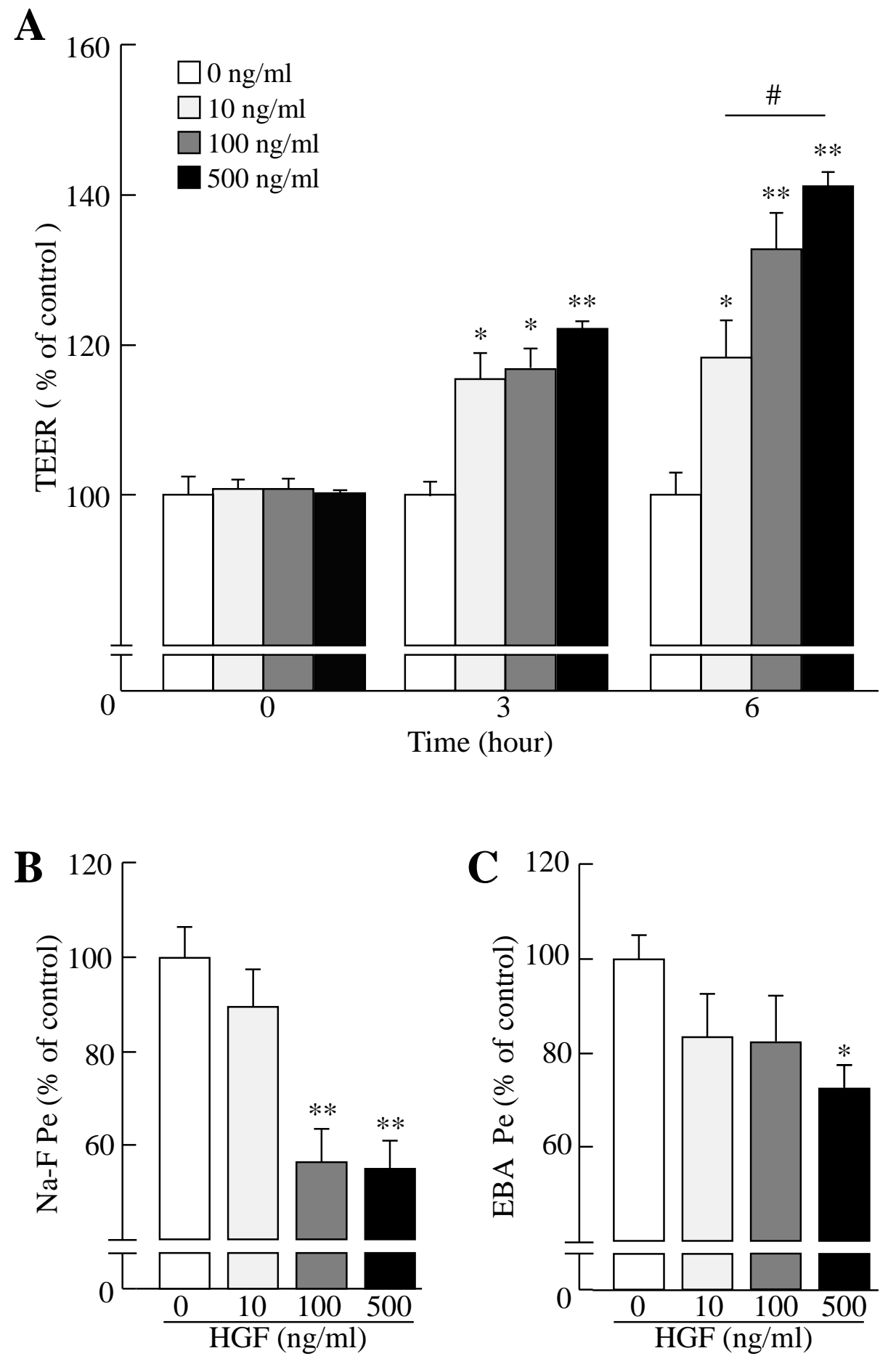

Fig. 2 
A

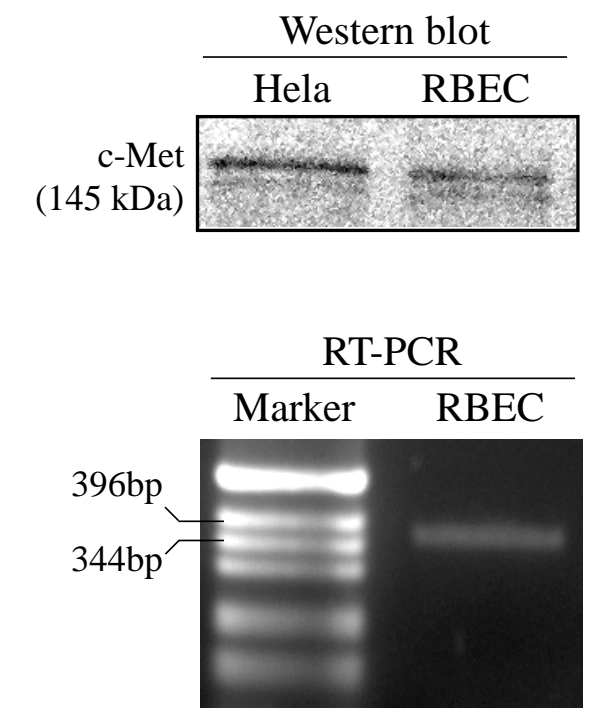

B

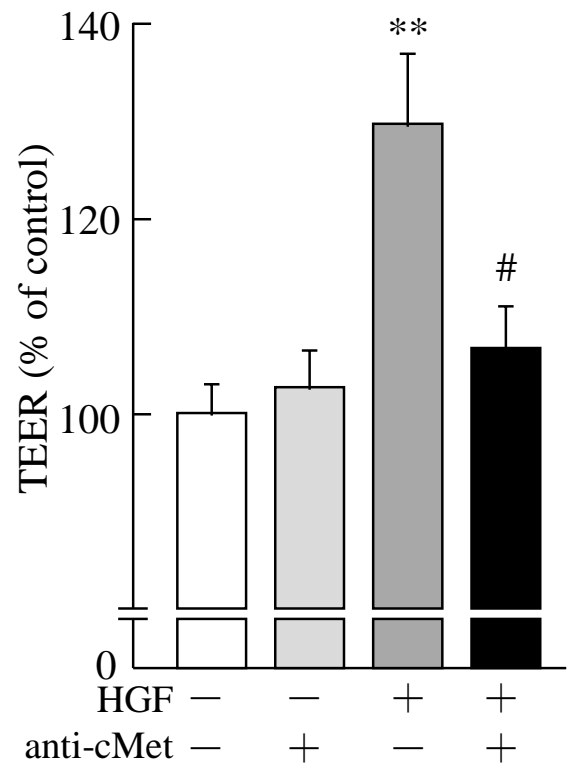

C

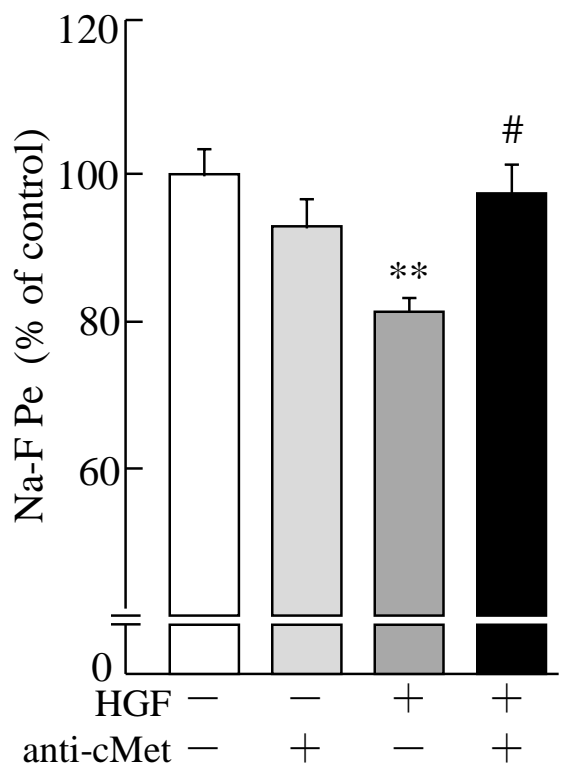

Fig. 3 
A

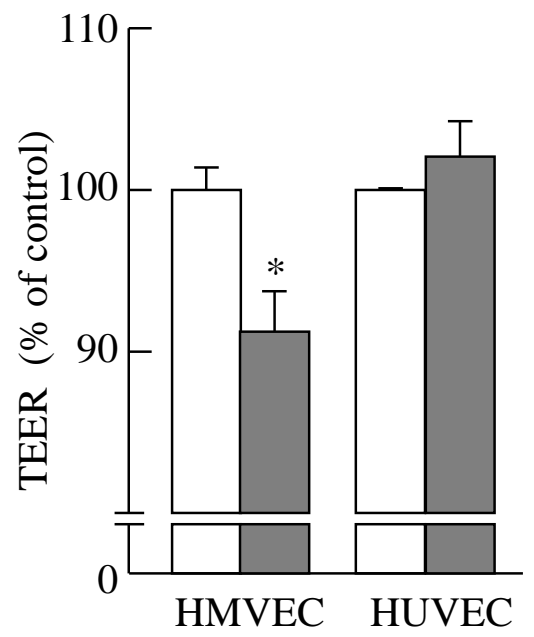

B

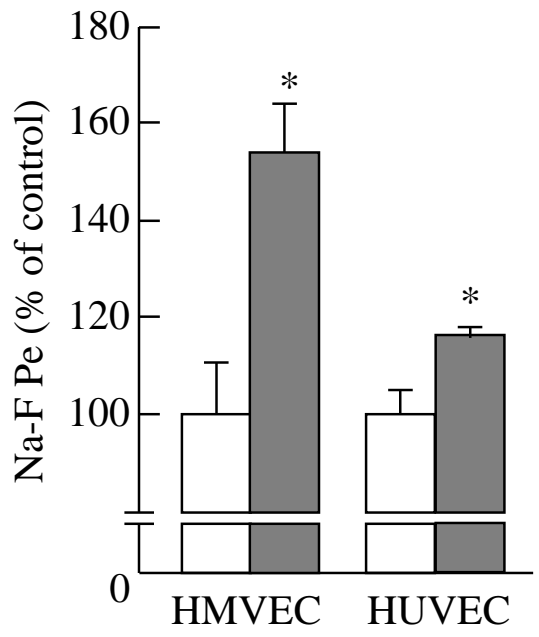

C

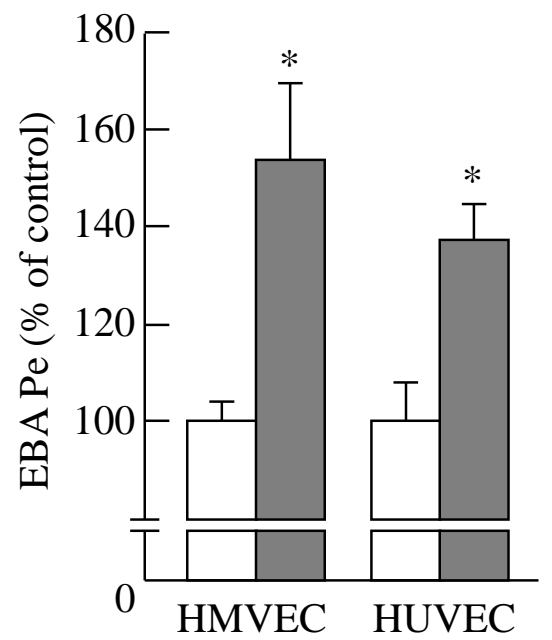

Fig. 4 


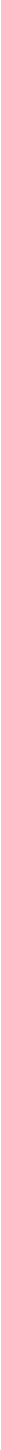

Fig. 5 


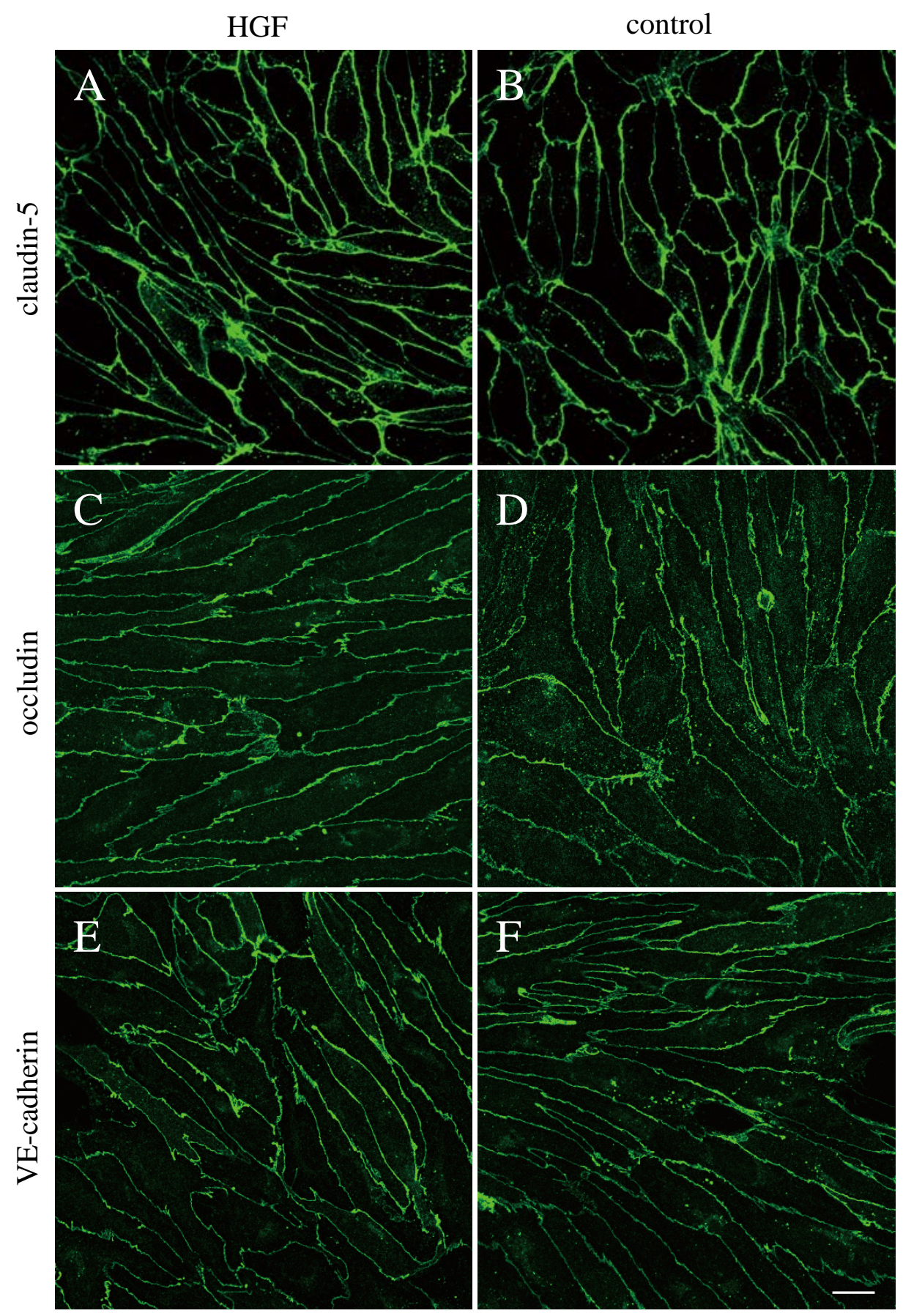

Fig. 6 
A

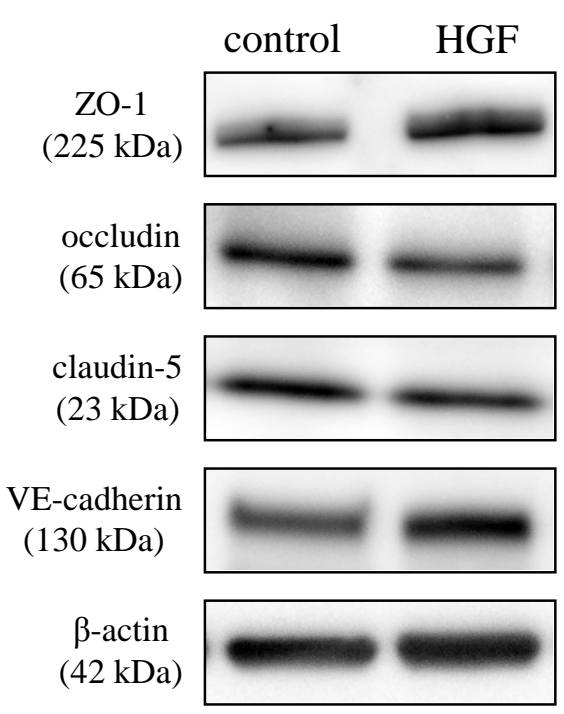

B

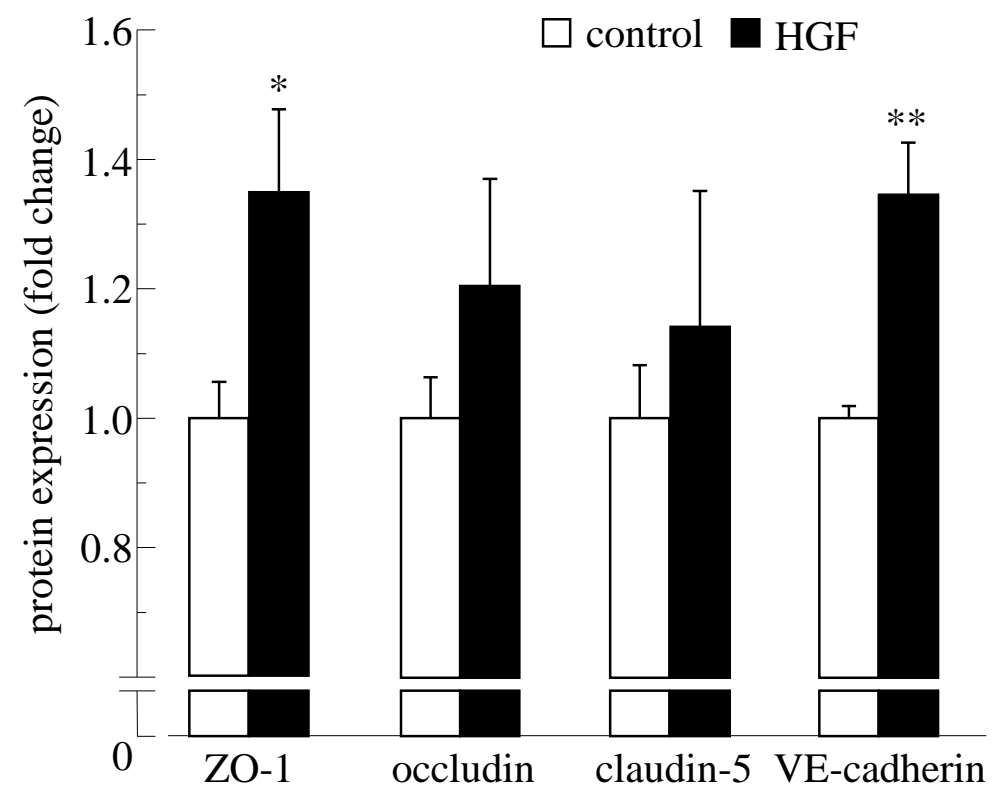

